KLEINE TEXTE FÜR VORLESUNGEN UND ÜBUNGEN HERAUSGEGEBEN VON HANS LIETZMANN

\title{
HISTORISCHE
}

\section{GRIECHISCHE INSCHRIFTEN}

BIS AUF ALEXANDER DEN GROSSEN

AUSGEWÄHLT UND ERKLÄRT

VON

ERNST NACHMANSON

PRIVATDOZENT IN UPPSALA

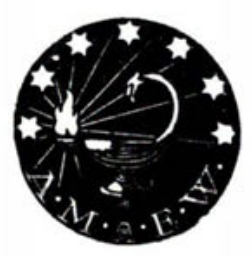

BONN

A. MARCUS UND E. WEBER'S VERLAG 